\title{
Pesquisa de trematódeos digenéticos em Heleobia spp. (Mollusca: Hydrobiidae) em área de ocorrência da Ehrlichiose monocítica equina, no Rio Grande do Sul, Brasil
}

\author{
Research of trematodes digenetics from Heleobia spp. (Mollusca: Hydrobiidae) in \\ area of occurrence of equine monocytic ehrlichiosis, in Rio Grande do Sul, Brazil
}

\author{
Helen Silveira Coimbra ${ }^{*}$, Luiz Filipe Damé Schuch', Gertrud Muller², \\ Carolina Lambrech Gonçalves ${ }^{1}$, Cristina Zambrano ${ }^{1}$, Marta Elaine Bastos Oyarzabal ${ }^{3}$, \\ Luciana de Souza Prestes', Mário Carlos Araujo Meireles' ${ }^{1}$
}

| | | | | | | | | | | | | | | | | | | | | | | | | | | | | | | | | | | | | | | | | | | | | | | | | | | | | | | | | | | | | | | | | | | | | | | | | | | | | | | | | | | | | | | | | | | | | | | | | | | | | | | | | | | | | | | | | | | | | | | | | | | | | | | | | | | | | | | | | | | | | | | | | | | | | | | | | | | | | | | | | | | | | | | | | | | | | | | | | | | | | | | | | | | | | | | | | | | | | | | | | |

\begin{abstract}
RESUMO: A ehrlichiose monocítica equina (EME) na regiáo Sul do Rio Grande do Sul tem demonstrado ser importante nas criaçóes de cavalos Crioulos. A enfermidade foi relatada e diagnosticada como causa de diarreia, prejuízos com tratamentos e com a morte de equinos náo estabulados, sendo apontada como um fator limitante na criação de equinos em algumas regiōes. $\mathrm{O}$ modo de transmissão pela via oral, intermediada por trematódeos em ambientes aquáticos, tem sido sustentado. Caracóis dulciaquícolas estão envolvidos como hospedeiros intermediários de trematódeos albergadores de Neorickettsia risticii. Um total de 16.846 caracóis Heleobia foi coletado nos municípios de Arroio Grande, Rio Grande, Palmares do Sul e Santa Vitória do Palmar, 92,2\% dos quais foram encontrados nas raízes de aguapés (Eichornea spp.). A frequência de trematódeos presentes nos caracóis variou de 2,3 a $12,8 \%$ nas propriedades coletadas. Foram encontrados três tipos de cercárias, morfotipo 1, morfotipo 2 e morfotipo 3, e dois morfotipos de metacercárias nos caracóis. Um total de 357 insetos da ordem Odonata foi coletado, fases de metacercárias foram encontradas no tegumento da subordem Anisoptera com frequência de 5,3\%. Mais estudos são necessários para identificar as fases larvais encontradas, bem como para conhecer o hospedeiro definitivo, identificar o parasito adulto e a relação de seu ciclo de vida com a ocorrência da ehrlichiose monocítica equina.
\end{abstract}

PALAVRAS-CHAVE: trematódeos; Heleobia spp.; Neorickettsia risticii.

\begin{abstract}
The equine monocytic ehrlichiosis in the region South of the Rio Grande do Sul has demonstrated to be important in the creations of Crioulo horses. It has been reported as cause of diarrhea in equine not surround and as cause of losses with treatments and death of the animals, being pointed as a limited factor in the range breeding in some regions. The way of transmission for the oral way, intermediated for trematodes in aquatic environments, has been supported. Freshwater snails are involved as intermediate hosts of trematodes and harbor of the Neorickettsia risticii. A total of 16,846 Heleobia snails had been collected in the cities of Arroio Grande, Rio Grande, Palmares do Sul and Santa Vitoria do Palmar, 92.2\% of which had been found in the roots of aquatics plants (Eichornea spp.). The frequency of trematodes present in the snails varied of 2.3 to $12.8 \%$ in the collected regions. Three types of cercariae were found, morphology type 1, morphology type 2 and morphology type 3 , and two morphologic type of metacercariae of the snails. A total of 357 insects of the Odonata order were collected, stages of metacercariae had been found in the tissues of suborder Anisoptera with $5.3 \%$ of frequency. More studies are necessary for identification of the joined larval phases, as well as knowing the host definitive and identifying the adult parasite and the relation of its cycle of life with the occurrence of equine monocytic ehrlichiosis.
\end{abstract}

KEYWORDS: trematodes; Heleobia spp.; Neorickettsia risticii.

\footnotetext{
'Faculdade de Veterinária; Universidade Federal de Pelotas (UFPEL) - Pelotas (RS), Brasil ${ }^{2}$ Instituto de Biologia; UFPEL - Pelotas (RS), Brasil.

${ }^{3}$ Faculdade de Veterinária; Universidade Federal do Rio Grande do Sul (UFRGS) - Porto Alegre (RS), Brasil.

*Autor correspondente: coimbrahs@gmail.com

Recebido em: 12/12/2011. Aceito em: 30/04/2013
} 


\section{INTRODUÇÃO}

A Ehrlichiose monocítica equina (EME) é uma doença infecciosa não contagiosa causada pela Neorickettsia risticii. A diarreia é a principal forma clínica e ocorre em 30\% dos casos (RiкiнisA, 1998). A enfermidade para o Rio Grande do Sul tem demonstrado ser importante nas criaçóes de cavalos Crioulos, em razão de prejuízos com tratamentos e morte de animais, e foi apontada como um fator limitante na criação em algumas regiôes (DuTRA et al., 2001; Coimbra, 2003). Desde 1999, nas épocas de verão, em propriedades localizadas próximas a lagoas de água doce, a EME foi diagnosticada (Dutra et al., 2001; CoImBra, 2003; Coimbra, 2010).

Para o entendimento do modo de transmissão da EME, estudos com vários vetores foram realizados e, atualmente, o modo de transmissão pela via oral, intermediado por trematódeos digenéticos em ambientes aquáticos, tem sido sustentado (Barlough et al., 1998; RiKinisa, 1998; Kanter et al., 2000; Pusterla et al., 2000; Coimbra et al., 2005).

Os trematódeos digenéticos têm um ciclo de vida complexo envolvendo dois a quatro hospedeiros. Em todos os ciclos conhecidos, o primeiro hospedeiro é um molusco, geralmente um caracol. Com poucas exceçôes, o hospedeiro definitivo, que contém o adulto, é um animal vertebrado (THATcher, 1993).

No município de Arroio Grande, RS, em propriedade localizada próxima à Lagoa Mirim, onde casos de EME foram confirmados, caracóis do gênero Heleobia foram identificados como positivos para $N$. risticii. Três espécies foram identificadas nessa região, $H$. piscium, $H$. parchappei e $H$. $d a-$ visi (Coimbra et al., 2005).

Os caracóis Heleobia spp. pertencem ao filo Mollusca, classe Gastropoda, subclasse Prosobranchia e família Hydrobiidae, e estão presentes em várias regiốes da planície costeira, do Rio Grande do Sul (Silva, 1993; Lanzer, 2001; Silva; Veitenheimer-Mendes, 2004). São encontrados abundantemente nas raízes de macrófitas aquáticas que estão presentes em arroios, rios, lagoas, canais de irrigação e de drenagem nas propriedades.

De acordo com FLores; BRUGNi (2006), caracóis do gênero Heleobia estão envolvidos como hospedeiros intermediários de trematódeos digenéticos; a espécie Catatropis hatcheri n. sp. (Digenea: Notocodylidae) foi encontrada parasitando Heleobiahatchery. Coimbra et al. (2005) encontraram cercárias do tipo Parapleurolophocercouscercariae parasitando caracóis $H$. piscium, infectadas com o DNA da $N$. risticii.

Barlough et al. (1998) estudaram caracóis da família Pleuroceridae do gênero Juga como vetores de trematódeos portadores de $N$. risticii. Pusterla et al. (2000) reproduziram experimentalmente a EME em equinos inoculando fases de esporocistos e cercárias coletadas de caracóis da espécie Juga yrekaensins. KANTER et al. (2000) e MотT et al. (2002) identificaram $N$. risticii em cercárias virguladas, Xiphidiocercariae, albergadas em caramujos do gênero Elimia, incluindo as espécies $E$. livescense e $E$. virginica. As cercárias desse tipo são características de trematódeos digenéticos, que utilizam como segundo hospedeiro intermediário um inseto.

Em pesquisa com insetos aquáticos, CHAE et al. (2000) e Мотт et al. (2002) encontraram as fases de metacercárias infectadas com $N$. risticii, sugerindo que a riquétsia tenha sido transmitida durante os estágios de desenvolvimento do trematódeo.

Pusterla et al. (2003) encontraram trematódeos Lecithodendrium sp. e Acanthatrium sp. parasitando baço e intestino de morcegos e andorinhas em área enzoótica para EME no norte da Califórnia. Tanto as andorinhas quanto os morcegos parasitados foram positivos para o DNA de $N$. risticii por PCR, sugerindo que a infecção por $N$. risticii ocorreu veiculada pelo trematódeo. GiBson et al. (2005) encontraram DNA de $N$. risticii em trematódeos da espécie Acanthatrium oregonense que parasitavam o intestino de morcegos (Eptesicusfuscus) em região endêmica no estado da Pensilvânia, USA.

Este trabalho teve como objetivo identificar os trematódeos possíveis vetores de $N$. risticii, por meio da pesquisa em hospedeiros intermediários, caracóis do gênero Heleobia e insetos.

\section{MATERIAL E MÉTODOS}

Durante o período de 2006 a 2009, foram realizadas 16 coletas de caracóis do gênero Heleobia e de insetos (libélulas) como possíveis hospedeiros intermediários de trematódeos. As coletas foram realizadas em terras baixas da encosta sudeste do Rio Grande do Sul, em propriedades dos municípios de Arroio Grande, Rio Grande, Santa Vitória do Palmar e Palmares do Sul. Das coletas realizadas no período de estudo, 13 (treze) ocorreram em Arroio Grande e 3 (três) em propriedades dos municípios de Rio Grande e Palmares do Sul (2008) e Santa Vitória do Palmar (2009), conforme a notificação de doença clínica de casos de diarreia em cavalos, compatível com EME. Em Arroio Grande, porém, das 13 coletas, 8 foram realizadas (2006 a 2007) em duas localidades denominadas como propriedade 1 e propriedade 2 com o objetivo de verificar variação na presença de trematódeos no caracóis Heleobia spp. conforme a época do ano. As outras 5 coletas foram feitas na mesma localidade conforme a ocorrência clínica de cavalos com diarreia.

Em cada propriedade, foram estabelecidos três pontos de coletas de 3 metros lineares cada. Em todas as coletas de caracóis, diferentes substratos foram recolhidos - plantas aquáticas (aguapé - Eichornea spp. e erva-de-bicho - Polygonum spp.) e sedimento presente nos canais de irrigação, ou arroio. A amostragem das raízes das plantas (substratos) foi realizada utilizando uma peneira de $22 \mathrm{~cm}$ de diâmetro por $9,5 \mathrm{~cm}$ de profundidade. O sedimento de cada ponto foi coletado em até $3 / 4$ de balde de 5 litros de capacidade. Para a retirada dos caracóis, as raízes e o 
sedimento foram lavados vigorosamente em balde com água do local e passados em peneira, sendo os caracóis retirados manualmente e acondicionados em recipientes plásticos com água do local. No laboratório, foram contados e separados em placas de petri contendo água destilada para observação e recuperação de cercárias e metacercárias. Alguns caracóis foram dissecados para verificar a frequência de parasitismo pelos trematódeos. As cercárias e metacercárias oriundas dos caracóis foram coletadas em água destilada e mantidas sob $4^{\circ} \mathrm{C}$.

De novembro de 2007 a março de 2009, incluíram-se na pesquisa coletas de insetos (libélulas). Os insetos foram capturados com uso de puçá e mantidos em recipiente com álcool 70\% e depois dissecados para verificar a presença de metacercárias em seu tegumento. Os insetos capturados foram enviados para identificação e classificação ao departamento de Microbiologia e Parasitologia do Instituto de Biologia da Universidade Federal de Pelotas. Os caracóis foram enviados para o Laboratório de Malacologia do departamento de Zoologia da Universidade Federal do Rio Grande do Sul para identificação, de acordo com Polígrafo não publicado, "Moluscos Límnicos do Rio Grande do Sul: Reconhecendo gêneros de Gastropodas", informação in litteris de Veitenheimer-Mendes; Silva (2004).

\section{RESULTADOS E DISCUSSÃO}

Nas coletas realizadas no período de um ano (2006 a 2007), em Arroio Grande, nas duas propriedades foram coletados 7.630 caracóis Heleobia spp., e a maior densidade dos gastrópodes foi observada nas raízes de aguapés onde 92,2\% (7.037) dos caracóis foram encontrados; no sedimento, encontraram-se 6,2\% (477) e nas raízes de erva-de-bicho, 1,5\% (116).

Em todos os substratos coletados, foram identificadas espécies de H. robusta (Silva; Veitenheimer-Mendes, 2004) e H. piscium já identificados na região (CoIMBra, 2003; CoImbra et al., 2005) (Fig. 1) nas formas jovens e adultas. A espécie $H$. piscium foi encontrada nas duas propriedades, enquanto a $H$. robusta somente na propriedade 1 . Fatores bióticos e abióticos, como a salinidade, a temperatura da água e a presença de substrato, podem interferir tanto na presença quanto na densidade populacional de determinadas espécies de Heleobia (Francesco; ISLA, 2004).

Dentre os 7 gêneros de Hydrobiidae representados no continente sul-americano, Heleobia é o que representa maior diversidade e distribuição com 71 espécies (Hersheler; THOMPSON, 1992). No município de Arroio Grande, já foram identificados $H$. piscium, $H$. parchappei e $H$. davisi em raízes de aguapés por Coimbra et al. (2005).

$\mathrm{Na}$ avaliação de frequências estacionais para presença de trematódeos nos caracóis nas duas propriedade de Arroio Grande estudadas no período de 2006 a 2007, foram encontradas na propriedade 1 as maiores quantidades de cercárias nos caracóis no veráo, com frequência de 19,35\%; no outono, 10,25\%; no inverno, 5\%; e na primavera, $17,33 \%$ (Fig. 2). Na propriedade 2 , em razáo do manejo nos canais de irrigação e uso de produtos químicos na limpeza dos canais com a retirada de toda a vegetação, em dois momentos não se obtiveram caracóis nos substratos estudados. Assim, na propriedade 2, as frequências puderam ser observadas nas estaçóes nas quais foi possível coletar caracóis para pesquisa das cercárias. Dessa forma, no outono, foi encontrada uma frequência de $11,11 \%$ e no inverno, 0\%. Não houve emissão ou presença de cercárias nos caracóis coletados (Fig. 2).

De novembro de 2007 a março de 2009, foram coletados um total de 9.216 caracóis Heleobia e um total de 357 insetos da ordem Odonata, classificados nas subordens

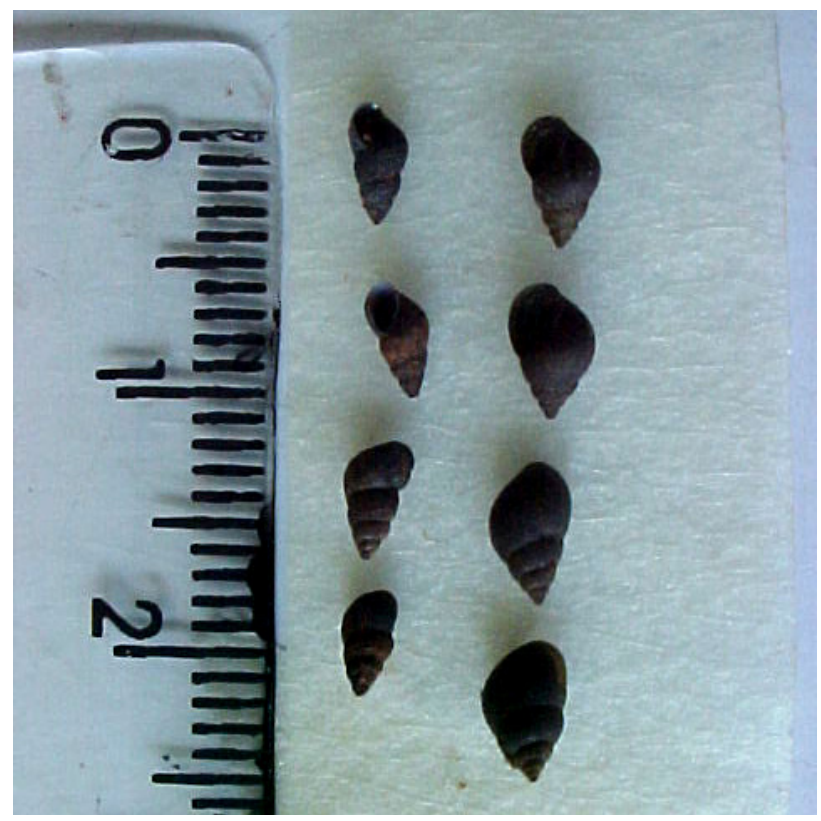

Figura 1. Heleobia robusta (esquerda) e Heleobia piscium (direita) encontrados nas raízes de aguapés, canais de irrigação das propriedades de estudo.

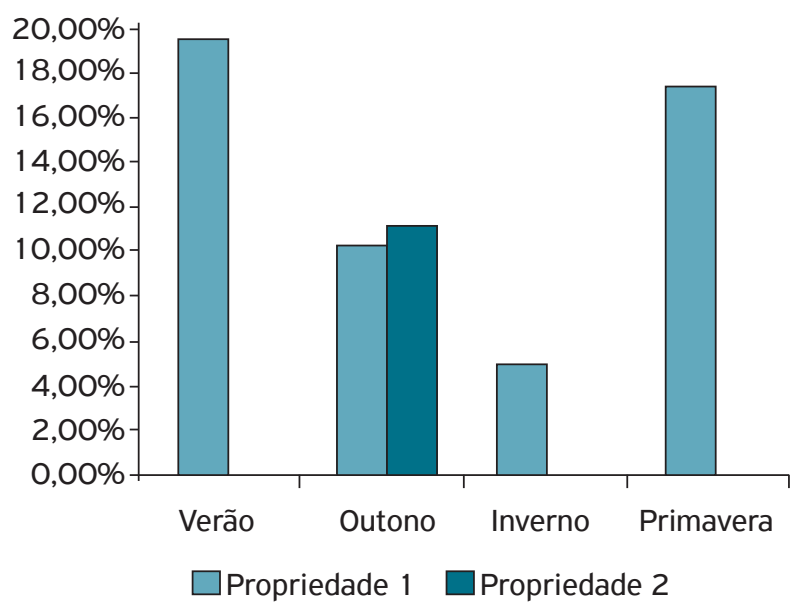

Figura 2. Taxa de parasitismo em caracóis Heleobia spp. coletados em Arroio Grande no período de um ano. 
Anisoptera (320) e Zigoptera (37). Nos insetos dissecados, foi verificada a fase de metacercária somente na subordem Anisoptera, com frequência de 5,3\% (17/320). Nos insetos, a metacercária pode apresentar diferentes estágios de maturidade (BODDEKe, 1960), o que pode ser observado nas diferentes formas que foram encontradas (Fig. $3 \mathrm{~A}, \mathrm{~B}$ e C). Libélulas da subordem Anisoptera foram citadas como segundo hospedeiro intermediário do Prosthogonimus ovatus, um trematódeo digenético parasito de aves, e metacercárias foram encontradas em diferentes fases de desenvolvimento no tegumento do inseto (Boddeke, 1960). Essa espécie Prosthogonimus ovatus foi encontrada como parasita de três espécies de aves aquáticas na região Sul do Brasil (Monteiro et al., 2007) e como parasita de passeriforme na regiáo Sul do Rio Grande do Sul, Brasil (Mascarenhas, 2008).

Uma amostragem de 1.671 caracóis foi dissecada, sendo encontrada uma frequência de cercárias entre 2,3 e 12,8\%. Em Heleobia spp. oriundos de Arroio Grande, a frequência foi de 6,47\% (63/973), de Rio Grande foi 12,83\% (24/187), de Palmares do Sul foi zero (foram encontradas só as fases de metacercárias) e de Santa Vitória do Palmar, 4,72\% (18/381) (Tabela). Coimbra et al. (2005) encontraram em Arroio Grande uma frequência de 16,6\% de trematódeos parasitando caracóis Heleobia spp.

Ambas as espécies de Heleobia encontradas albergavam fases de rédias e cercárias. Para verificar a emissão de cercárias pelos caracóis, foram observadas diariamente 10 placas contendo 50 caracóis cada. Nos primeiros 5 dias de observação, a emissão de aproximadamente 200 cercárias foi verificada a cada 24 horas, em pelo menos 3 placas e persistente por até 17 dias, principalmente no período noturno. Foram encontrados 3 tipos de cercárias, classificadas como morfotipo 1 , morfotipo 2 e morfotipo 3.

As cercárias classificadas como morfotipo 1 apresentavam características de corpo em forma elíptica, intensamente pigmentado. Constatou-se presença de três ocelos fortemente pigmentados posicionados logo abaixo da ventosa oral, sendo os laterais mais facilmente observáveis que o ocelo central, uma vez que se destacavam por apresentarem uma faixa sem pigmento com suas faces internas. Observou-se ausência de acetábulo. Outro aspecto desse morfotipo é que se encista rapidamente no meio externo em metacercária fortemente pigmentada com características compatíveis com as cercárias do morfotipo 1, como a presença de ocelos fortemente pigmentados (Fig. 4). Essas metacercárias foram denominadas de metacercárias morfotipo 1 (Fig. 5). O conjunto de caracteres possíveis de serem observados indica que essa cercária originará trematódeos digenéticos das famílias Notocotylidae ou Pronocephalidae de acordo com Schell (1970) e Frandsen; Christensen (1984). Os moluscos, hospedeiros intermediários, caracterizam-se por serem
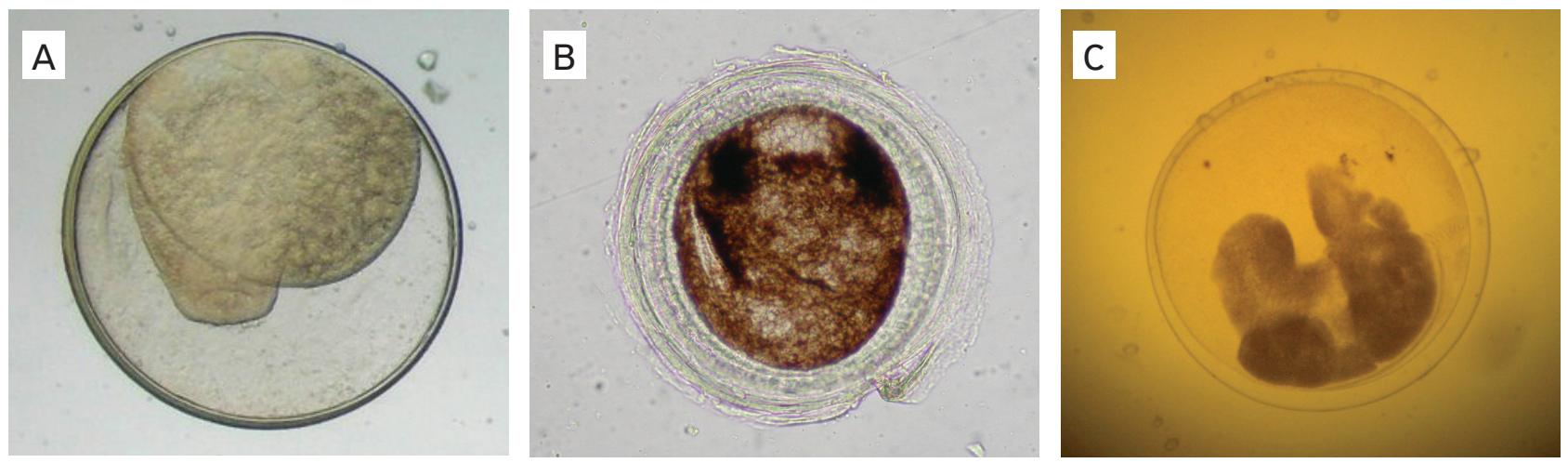

Figura 3. Metacercárias encontradas no tegumento das libélulas dissecadas. Aumento de 200x. Zoom digital.

Tabela. Taxa de parasitismo das fases de cercárias e metacercárias encontradas nos caracóis Heleobia spp. coletados em Rio Grande, Arroio Grande, Palmares do Sul e Santa Vitória do Palmar de 2006 a 2009.

\begin{tabular}{|c|c|c|c|c|c|}
\hline \multirow[b]{2}{*}{ Locais } & \multirow{2}{*}{$\begin{array}{c}N^{\circ} \text { de caracóis } \\
\text { dissecados }\end{array}$} & \multicolumn{2}{|c|}{ Fase de cercária } & \multicolumn{2}{|c|}{ Fase de metacercária } \\
\hline & & $\begin{array}{c}N^{\circ} \text { de caracóis } \\
\text { parasitados }\end{array}$ & $\begin{array}{c}\text { Taxa de } \\
\text { parasitismo (\%) }\end{array}$ & $\begin{array}{c}\mathrm{N}^{\circ} \text { de caracóis } \\
\text { parasitados }\end{array}$ & $\begin{array}{c}\text { Taxa de } \\
\text { parasitismo (\%) }\end{array}$ \\
\hline Arroio Grande & 973 & 63 & 6,47 & 16 & 1,64 \\
\hline Rio Grande & 187 & 24 & 12,83 & 10 & 5,34 \\
\hline Palmares do Sul & 130 & 0 & - & 3 & 2,3 \\
\hline $\begin{array}{l}\text { Santa Vitória do } \\
\text { Palmar }\end{array}$ & 381 & 18 & 4,72 & 5 & 1,3 \\
\hline Total & 1671 & 105 & 6,26 & 34 & 2,03 \\
\hline
\end{tabular}


gastrópodes operculados, como no presente caso exemplares de Heleobia spp.

As cercárias do morfotipo 2 apresentavam as características de corpo pigmentado, sem manchas ocelares e com presença de estilete na porção oral. As medidas encontradas foram de 0,24 mm em comprimento total, 0,10 mm comprimento de cauda e 0,14 mm de corpo (Fig. 6A e B). Nas placas que apresentavam as cercárias morfotipo 2 , foi verificado que não encistavam, ou seja, não foi observada nenhuma estrutura com características de metacercária no ambiente externo (placa de petri). O observado foi que, após um período (acima de quatro horas), essas cercárias perdiam totalmente a motilidade e a vitalidade. É provável que as cercárias de morfotipo 2 pertençam a uma espécie de trematódeo que necessite mais de um hospedeiro intermediário para formar a fase infectante de metacercária. Ainda, foram encontradas metacercárias presentes no interior de Heleobia spp., com frequência de 2,03\% (34/1671) (Tabela). Essas metacercárias foram classificadas como morfotipo 2 (Fig. 7). Essas características reafirmam uma possibilidade de esse trematódeo necessitar de um segundo hospedeiro intermediário.

As cercárias de morfotipo 3 foram encontradas em duas das coletas realizadas e em pequena quantidade quando comparado com os outros morfotipos, o que não permitiu a coleta de mais dados. $\mathrm{O}$ morfotipo 3 apresentou características como cauda bífida, de $0,105 \mathrm{~mm}$ de cauda e de 0,15 de corpo, e um comprimento total de 0,255 mm (Fig. 8).

Diversos tipos de cercárias de trematódeos foram descritos no Brasil por diferentes autores desde o início do século passado. Entre as larvas mais comumente encontradas, destacam-se as cercárias de cauda bifurcada (entre as quais

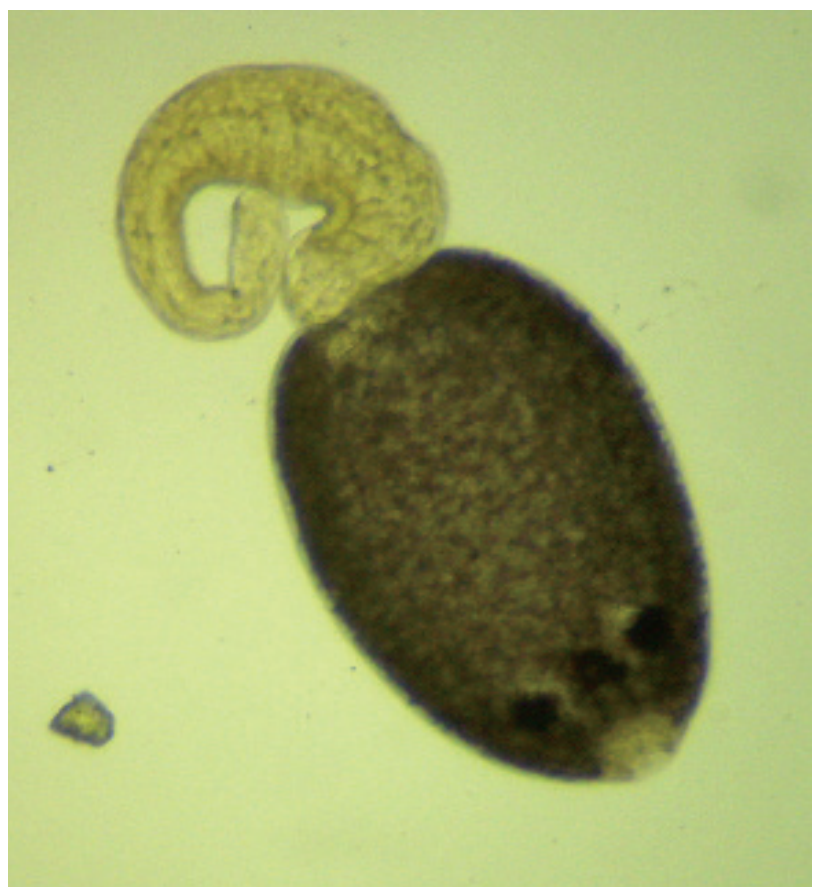

Figura 4. Cercária morfotipo 1. Aumento de 40x. Zoom digital.

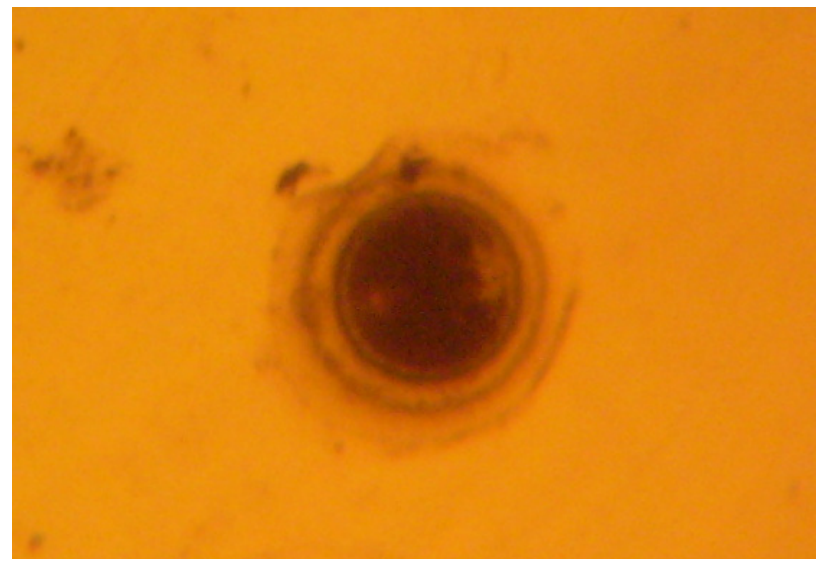

Figura 5. Metacercária morfotipo 1, encontrada presa no fundo da placa. Aumento 40x. Zoom digital
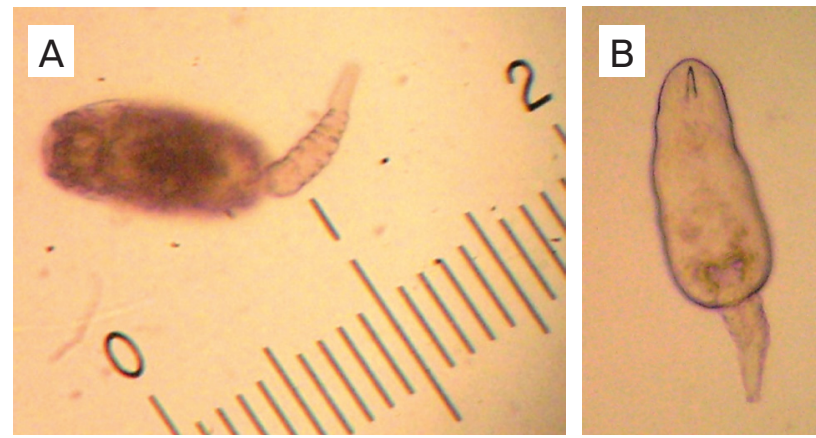

Figura 6. Cercária morfotipo 2. Aumento 10x. Zoom digital

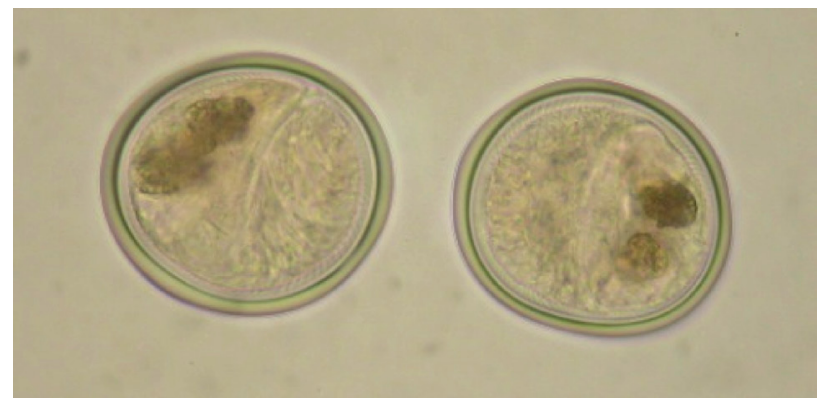

Figura 7. Metacercária morfotipo 2, encontrada nos tecidos e interior da concha dos Heleobia spp. Aumento 200x.

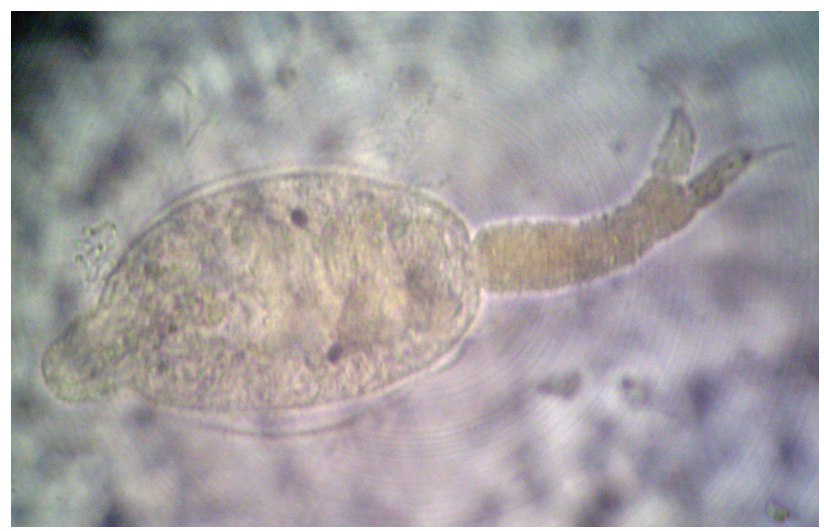

Figura 8. Cercária morfotipo 3. Aumento 40x. Zoom digital. 
está inclusa a de Schistossoma mansoni) e de cauda simples (como a de Fasciola hepatica) que apresentam importância médico-veterinária. Uma gama de formas diferentes pode ser encontrada em moluscos. Para algumas dessas larvas, os hospedeiros definitivos já são conhecidos, mas para a grande maioria ainda não foi possível fazer a identificação, pois os adultos são parasitos de peixes, anfíbios, répteis, aves ou mamíferos, alguns ainda desconhecidos para a ciência (Melo, 2007).

Com os resultados encontrados, podemos concluir que os caracóis do gênero Heleobia e insetos da ordem Odonata, subordem Anisoptera, são hospedeiros intermediários de trematódeos por apresentarem pelo menos três morfotipos distintos de cercárias (caracóis) e fases de metacercárias (caracóis e insetos) nas localidades estudadas. As maiores frequências de caracóis parasitados ou emitindo trematódeos nos períodos mais quentes do ano sugerem uma relação na sazonalidade e endemicidade de ocorrência da EME, uma vez que os cavalos criados em áreas de alagados apresentam maior contato com o ambiente potencialmente infectado pelos trematódeos que podem conter a $N$. risticii. No entanto, mais estudos são necessários para a identificação das fases larvais encontradas, bem como para conhecer o hospedeiro definitivo e identificar o parasito adulto e a relaçấo de seu ciclo de vida com a ocorrência da ehrlichiose monocítica equina.

| | | | | | | | | | | | | | | | | | | | | | | | | | | | | | | | | | | | | | | | | | | | | | | | | | | | | | | | | | | | | | | | | | | | | | | | | | | | | | | | | | | | | | | | | | | | | | | | | | | | | | | | | | | | | | | | | | | | | | | | | | | | | | | | | | | | | | | | | | | | | | | | | | | | | | | | | | | | | | | | | | | | | | | | | | | | | | | | | | | | | | | | | | | | | | | | | | | | | | | | | | | | | | | REFERÊNCIAS

BARLOUGH, J.E.; REUBEL, G.H.; MADIGAN, J.E.; VREDEVOE, L.K; MILLER, P.E.; RIKIHISA, Y. Detection of Ehrlichia risticii, the agent of Potomac horse fever, in freshwater stream snails (Pleuroceridae: Juga spp) from northern California. Applied and Environmental Microbiology, v.64, n.8, p.2888-2893, 1998.

BODDEKE, R. The life history of Prosthogonimus ovatus Rudolphi II the intermediate hosts. Tropical an Geographical Medicine, v.12, p.363-377, 1960.

CHAE, J.; PUSTERLA, N.; JOHNSON, E.; DEROCK, E.; LAWER, S.P; MADIGAN, J.E. Infection of aquatic insects with trematode metacercariae carrying Ehrlichia risticii, the cause of Potomac horse fever. Journal Medical Entomology, v.37, n.4, p.619625, 2000.

COIMBRA, H.S. Erliquiose monocítica equina no Rio Grande do Sul: Aspectos clínicos, anátomo-patológicos e epidemiológicos. 2003. 40f. Dissertação (Mestrado em Ciências - Área de Veterinária Preventiva) - Faculdade de Veterinária, Universidade Federal de Pelotas, Pelotas, 2003.

COIMBRA, H.S.; SCHUCH, L.F.D.; VEITEINHEMER-MENDES, M.C.A.; MEIRELES, M.C.A. Neorickettsia (Ehrlichia) risticii no Sul do Brasil: Heleobia spp (Mollusca: Hydrobilidae) e Parapleurolophocercouscercariae (Trematoda: Digenea) como possíveis vetores. Arquivos do Instituto Biológico, v.72, n.3, p.325-329, 2005.

COIMBRA, H.S. Ocorrência clínica da Erliquiose monocítica equina e pesquisa de formas jovens de trematódeos em Heleobia spp (Mollusca: Hydrobiidae) em terras baixas da encosta Sudeste do Rio Grande do Sul. 2010. 48f. Tese (Doutorado em Ciências - Área de Veterinária Preventiva, Sanidade Animal) - Faculdade de Veterinária, Universidade Federal de Pelotas, Pelotas, 2010.

DUTRA, F.; SCHUCH, L.F.D.; DELUCCHI, E.; CURCIO, B.R.; COIMBRA, H.S.; RAFFI, M.B.; DELLAGOSTIN, O.; RIET-CORREA, F. Equine monocytic Ehrlichiosis (Potomac horse fever) in horses in Uruguay and southern Brazil. Journal Veterinary Diagnostic Investigation, v. 13, n.5, p.433-437, 2001.

FLORES, V.; BRUGNI, N. Catatropis hatcheri n. sp. (Digenea: Notocotylidae) from Heleobia hatchery (Prosobranchia: Hydrobiidae) and notes on its life-cycle in Patagonia, Argentina. Systematic Parasitology, v.63, n.2, p.111-118, 2006.

FRANCESCO, C.G De; ISLA, F.I. The life cycle and growth of heleobia australis (D’orbigny, 1835) and $h$. conexa (Gaillard, 1974) (gastropoda: rissooidea) in mar Chiquita coastal lagoon (Argentina). Journal of Molluscan Studies, v.70, p. 173-178, 2004.

FRANDSEN, F; CHRISTENSEN, N.O. An introductory guide to the identification of cercariae from African freshwater snails with special reference to cercariae of trematodes species of medical and veterinary importance. Acta Tropica, v.41, n.2, p.181-202, 1984.

GIBSON, K.E.; RIKIHISA, Y.; ZHANG, C.; MARTIN, C. Neorickettsia risticii is vertically transmitted in the trematode Acanthatrium oregonense and horizontally transmitted to bats. Environmental Microbiology, v.7, n.2, p.203-212. 2005.

HERSHELER, R.; THONPSON, F.G. A review of the aquatic gastropod subfamily Cochliopinae (Prosobranchia:Hydrobiidae). Malacological Review, Ann Arbor, v.5, p.1-140, 1992. Suplemento 1 .

KANTER, M.; MOTT, J.; OHASHI, N.; FRIED, B.; REED, S.; LIN, Y.C.; RIKIHISA, Y. Analysis of 16S rRNA and 51-kilodalton antigen gene and transmission in mice of Ehrlichia risticii in virgulate trematodes from Elimia Livescens snails in Ohio. Journal of Clinical Microbiology, v.38, n.8, p.3349-3358, 2000.

LANZER, R. Distribuição, fatores históricos e dispersão de moluscos límnicos em lagoas do sul do Brasil. Biociências, Porto Alegre, v.9, n.2, p.63-84, 2001. 
MASCARENHAS, C.S. Helminto e Atropodofauna de Paroariacoronata (Miller, 1776) (Passeriformes - Emberizidae). 2008. 40f. Dissertação (Mestrado em Parasitologia) - Instituto de Biologia, Universidade Federal de Pelotas, 2008.

MELO, A.L. Formas larvais de trematódeos em moluscos límnicos. In:_. Vigilância e controle e moluscos de importância epidemiológica. Diretrizes técnicas: Programa de vigilância e Controle da Esquistossomose (PCE). 2a ed. Série A: normas e manuais técnicos. Brasília, DF: Editora do Ministério da Saúde (MS), 2007. p.71-80.

MONTEIRO, C.M.; AMATO, J.F.R.; AMATO, S.B. Prosthogonimus ovatus (Rudolphi) (Digenea, Prosthogonimidae) em três espécies de aves aquáticas da região Sul do Brasil. Revista Brasileira de Zoologia, v.24, p.253-257, 2007.

MOTT, J.; MURAMATSU, Y.; SEATON, E.; MARTIN, C.; REED, S.; RIKIHISA, Y. Molecular analysis of Neorickettsia risticii in adult aquatic insects in Pennsylvania, in horses infected by ingestion of insects, and isolated in cell culture. Journal of Clinical Microbiology, v.40, n.2, p.690-693, 2002.

PUSTERLA, N.; JOHNSON, E.M.; CHAE, J.S.; MADIGAN, J.E. Digenetic trematodes, Acanthatrium sp. and Lecithodendrium sp., as vectors of Neorickettsia risticii, the agent Potomac horse fever. Journal Helminthology, v.77, n.4, p.335-339, 2003.

PUSTERLA, N.; MADIGAN, J.E.; CHAE, J.-S.; DEROCK, E.; JOHNSON, E.; PUSTERLA, J.B. Helminthic transmission and isolation of Ehrlichia risticii, the causative agent of Potomac horse fever, by using trematode stages from freshwater stream snails. Journal of Clinical Microbiology, v.38, n.3, p.12931297, 2000.

RIKIHISA, Y. Rickettsial diseases. In: REED, S.M.; BAYLY, W.M. Equine Internal Medicine. Philadelphia, USA: W.B. Saunders Company, 1998, p.112-123.

SHELL, S.C. How to know the trematodes. Dubuque: WM. C. Brown Co. Publishers, 1970. 355p.

SILVA, M.C.P.; VEITENHEIMER-MENDES, I.L. Nova espécie de Heleobia (Rissooidea, Hydrobiidae) para a Planície Costeira do sul do Brasil. Iheringia - Série Zoologia, Porto Alegre, v.94, n.1, p.89-94, 2004

SILVA, M.C.P. Dados morfológicos de Heleobia parchappei (Orbigny, 1835) (Prosobranchia, Hydrobiidae, Littoridininae). Iheringia - Série Zoologia, Porto Alegre, v.75, p.81-87, 1993.

THATCHER, V.E. Trematódeos Neotropicais. Amazonas, Brasil: Editora INPA, 1993. 553p.

VEITENHEIMER-MENDES, I.L; SILVA, M.C.P. Polígrafo Moluscos Límnicos do Rio Grande do Sul: Reconhecendo gêneros Gastropodas. Manuscrito não publicado, recurso de aulas práticas do curso de Ciências Biológicas e Pós-Graduação em Biologia Animal da Universidade Federal do Rio Grande do Sul UFGRS, Porto Alegre, 6p, 2004. 